\title{
The effect of combined Training Program on Sleep Hygiene among of girl's primary school students
}

Masoomeh masnabadi

MSc in Health Education, Department of Health Education, School of Health, Arak University of Medical Sciences, Arak, Iran.

Nasrin Roozbahani

* Assistant Professor of Health Education, Departman of Health Education, School of Health, Arak University of Medical Sciences, Arak, Iran.( Corresponding Author) roozbahani@arakmu.ac.ir

Mehboob Khorsandi

Professor of Health Education, Departman of Health Education, School of Health,

Arak University of Medical Sciences, Arak, Iran

Received: 01 September 2019

Accepted: 12 January 2020

Doi: 10.29252/ijhehp.8.1

\section{ABSTRACT}

Background and Objective: Sleep are among the basic human needs and play a key role in memory, learning processes, and the educational performance of children and adolescents. The present study aimed to determine the effect of combined Training Program on sleep Hygiene of girl students.

Materials and Methods: In this Quasi-experimental, 100 female primary school students in Arak were randomly assigned to two groups of intervention (50 people) and control (50 people). The data collection tool was a questionnaire on children's sleep habits that was completed by mothers and the higher score was the sign of sleep disorders. Educational intervention was conducted on the basis of predetermined goals and needs assessment was conducted via social network for mothers and students' education was performed via games and entertainment. Three months after the intervention, the questionnaires were completed again and the data were analyzed.

Results: In the intervention group, the score of sleep habits was significantly improved as to before the intervention (before: $53.22 \pm 5.44$, after $45.24 \pm 14.4$, $\mathrm{p}<0.001)$; however, there was no significant difference in the control group. The significant difference was observed in the subscales of resistance to bedtime, sleep duration, night waking, parasomnia and daytime sleepiness, but there was no significant difference in anxiety, respiratory disorder and sleep latency as to before the intervention.

Conclusion: The present study showed that using social network for maternal education and using games and entertainment for students' education are effective and improve students' sleep Hygiene.

Keywords: Sleep Hygiene, Student, Social network, Games Paper Type: Research Article.

Citation (Vancouver): masnabadi M, Roozbahani N, Khorsandi M. The effect of combined Training Program on Sleep Hygiene among of girl's primary school students. Iran J Health Educ Health Promot. Spring 2020;8(1): 23-34. [Persian]

Citation (APA): masnabadi M., Roozbahani N., Khorsandi M. (Spring 2020). The effect of combined Training Program on Sleep Hygiene among of girl's primary school students. Iranian Journal of Health Education \& Health Promotion., 8(1), 23-34. [Persian] 


\section{تاثير برنامه آموزشى تركيبى بر بهداشت خواب دانش آموزان دختر ابتدايى}

\section{جكيده}

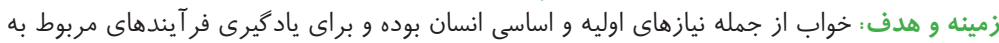

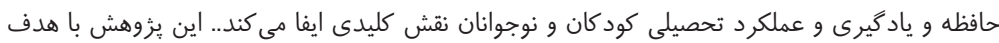

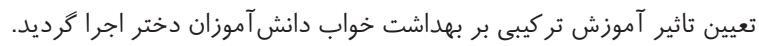

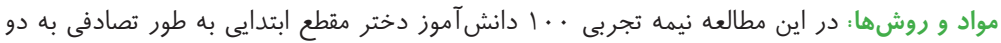

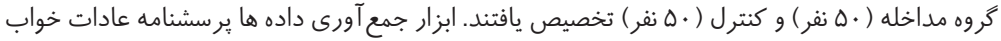

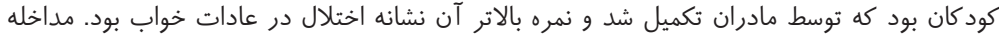

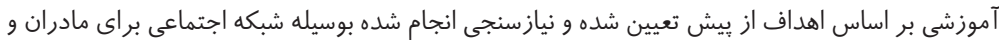

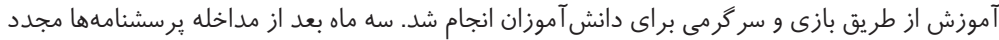

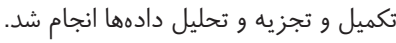

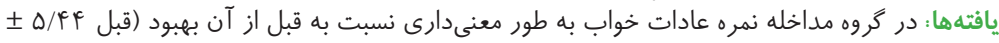

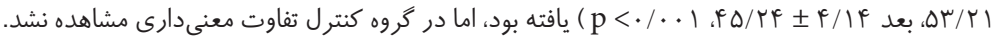

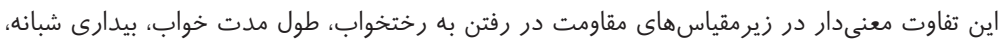

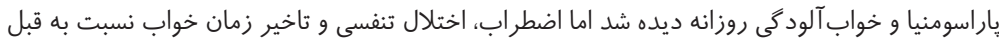

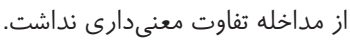

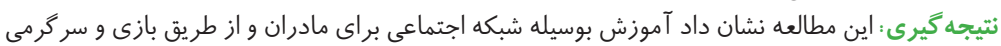

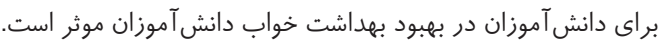

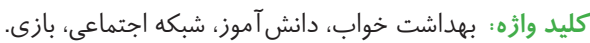
نوع مقاله : مطالعه يزوهشى.

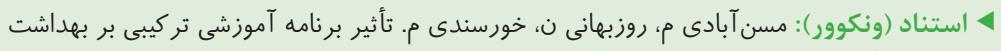

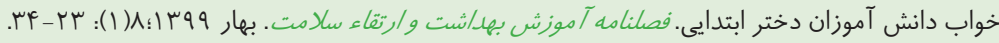

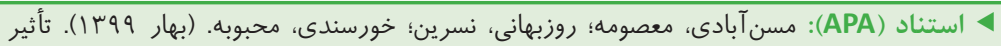

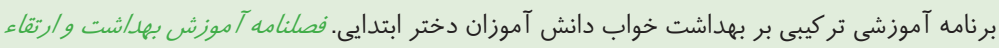

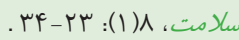

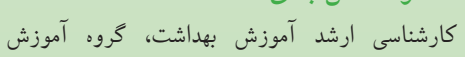

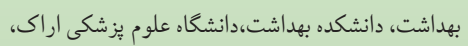

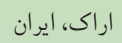

نسرين روزبهانى آراني دانشيار آموزش بهداشت، كروبه آموزش بهداشت، نهاني

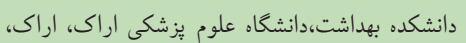

$$
\text { ايران. (نويسنده مسئول) }
$$

roozbahani@arakmu .ac.ir

$$
\text { محبوبه خور سندى أمتاد }
$$
استاد آموزش بهداشت، كروه آموزش بهداشت، دانشكده

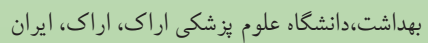

تاريخ د ريافت: 0

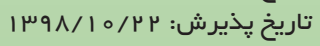


مهمترين اين عوامل مىتوان به سن اشاره نمود(Y). كودكان سنين

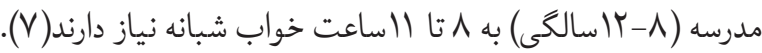
اخرجه اغلب مطالعات تجربى ثابت كردهاند كه كودكان و نوجوانان به طور متوسط به 9 ساعت خواب در طول شب احتياج دارند ولى نتايج تحقيقات مختلف نشان داده است كه PQ درصد كودكان و

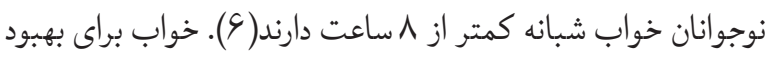

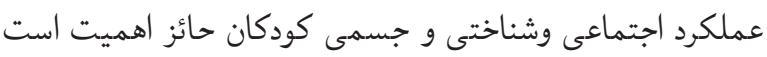
(9) با توجه به عواقب منفى خواب غيركافى، ميزان شيوع بالاى

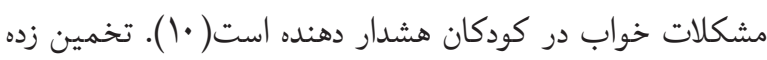
مىشود كه بيش از ه广\% كودكان در دوران كودكى اختلالات خواب را

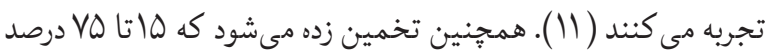

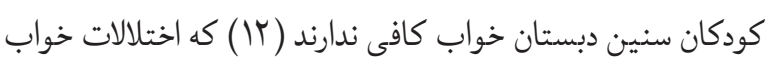
مى تواند به طور مستقيم و غيرمستقيم بر دانش آموزان و خانواده

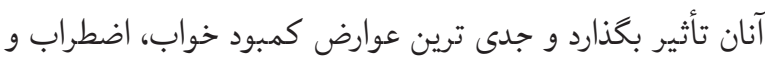

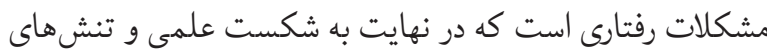
خانوادكى و روانى و اجتماعى منجر مىشود.(سآ آ يكى از شايعترين

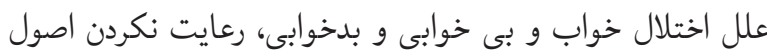
مربوط به بهداشت خواب مى باشد بهداشت خواب مجموعه اقداماتى

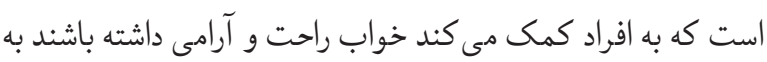

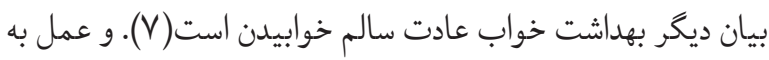
رفتارهايى كه باعث خواب خوب وارتقاء عملكرد روزانه افراد مىشود

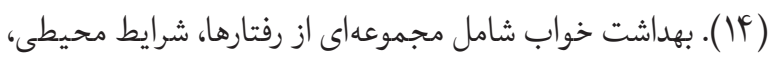
فاكتورهاى ديكر مرتبط با خواب است كه مىتواند در درمان بيمارانى كه از اختلالات خواب رنج مىبرند موثر باشد. فعاليتهاى بهداشت

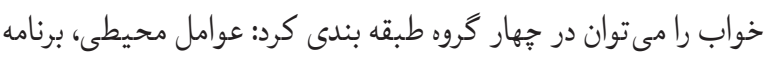

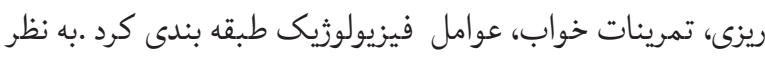
مىرسد كه آموزش بهداشت خواب دانش آموزان توسط والدين سبب بهبود سلامت كودكان مىشود( • (1). براساس مطالعات انجام شده،

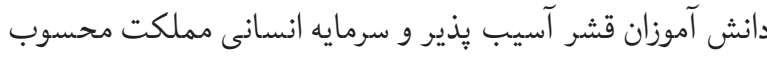

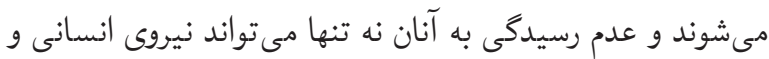

نزديك به يك سوم دوران زندگى ما در خواب مى گذرد ( (). خواب

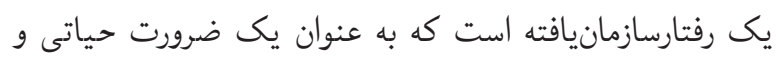
بر پايه ريتم بيولوزيك هرووز تكرارمىشود و از ديرباز مورد توجه

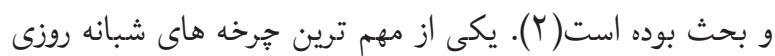

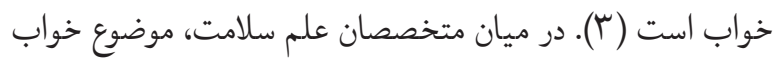
به دليل بُعد جسمى و روانى آن از اهميت اساسى برخوردار بوده است. مطالعات انجام شده دراين زمينه نشان مى دهد كه براى عموم

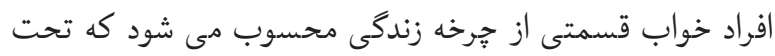

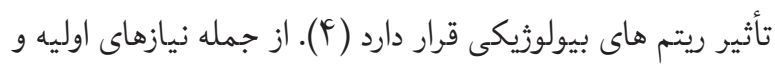

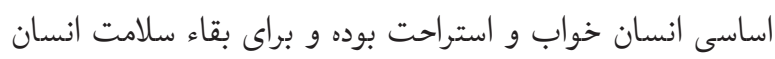

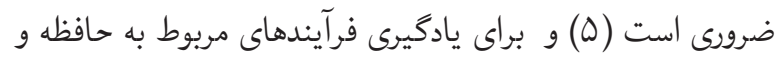
يادكيرى و عملكرد تحصيلى كودكان و نوجوانان نقش كليدى ايفا

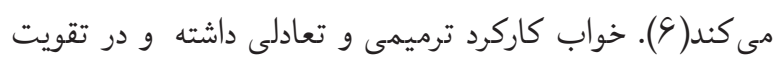

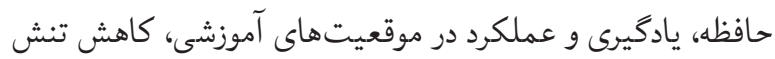
و اضطراب و فشارهاى عصبى و كمك براى بازيافت انرزى مجدد، تمركز بهتر حواس، سازكارى و لذت بردن از فعاليتهاى روزانه

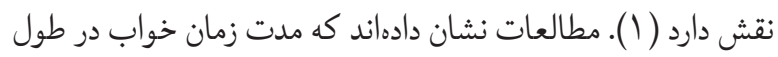

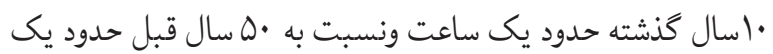

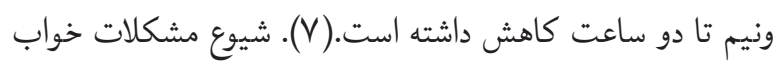
در جمعيت جهان بين MF-10 درصد گزارش شده است ودر ايران

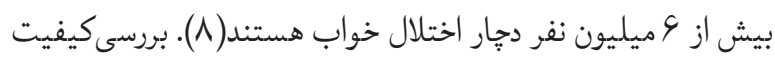

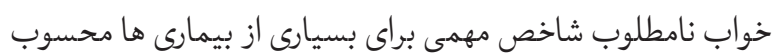

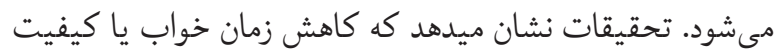
خواب، علاوه بر خستخى و كاهش كيفيت زندكى، اشكال در ترميم سلولى، نقص در حافظه و يادگيرى، ناراحتىهاى معدهاى و روده ای،

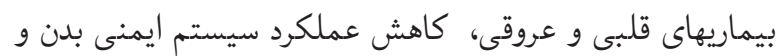
مرى زودرس را به دنبال دارد كه مى تواند باعث ايجاد مشكلات وتحميل هزينه هاى زياد به سيستم بهداشت و درمان شود (f).

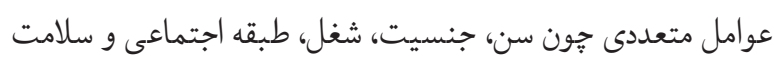

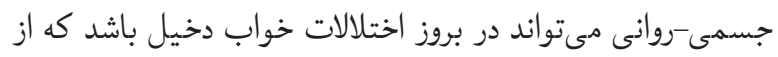


به ادامه حضور در مطالعه و انتقال دانش آموز به مدرسه ديخر بود.

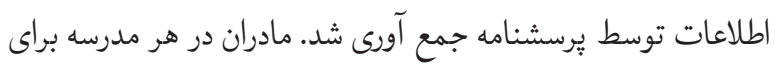

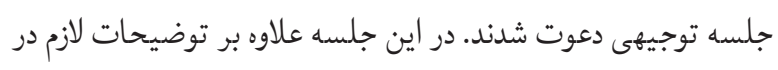

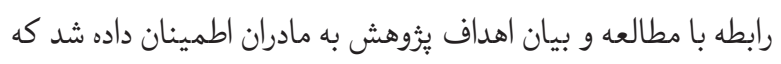

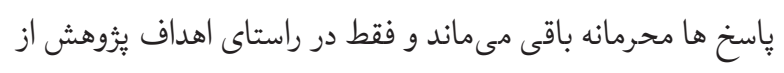

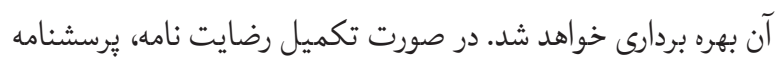

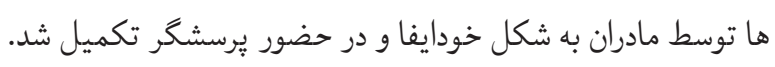

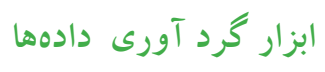

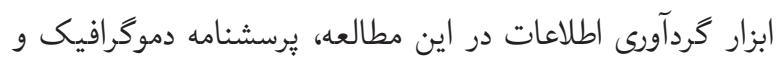

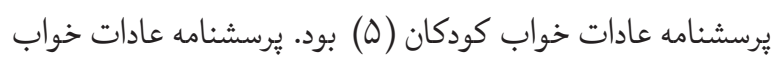
كودكان سب آيتم در ^ خرده مقياس دارد:

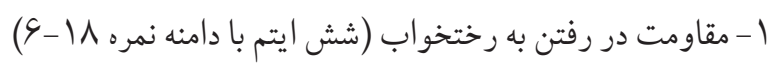
مانند ( كودى براى خوابيدن به حضور والدين در اتاق نياز دارد))

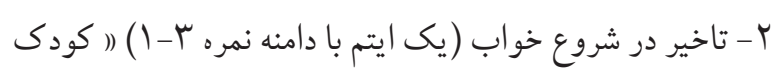
تا بيست دقيقه بعد از رفتن به رختخواب مى خوابد).

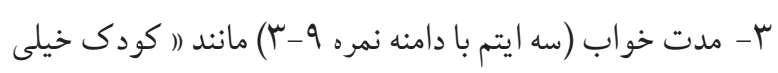
كم مى خوابد).

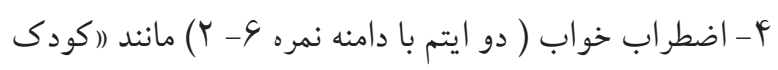
از خوابيدن در تاريكى مى ترسد)).

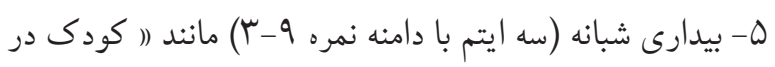

$$
\text { طول شب به رختخواب فرد ديكرى مى رود)). }
$$

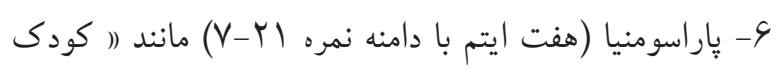

$$
\text { رختخواب خود را خيس مى كند). }
$$

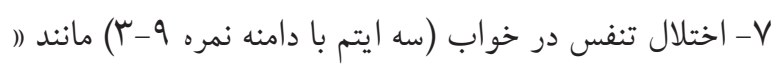

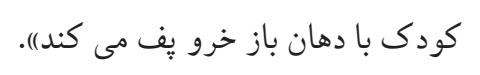

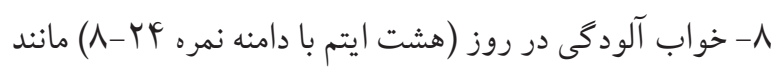

$$
\text { (( كودى با خلق بد از خواب بيدار مى شود)). }
$$

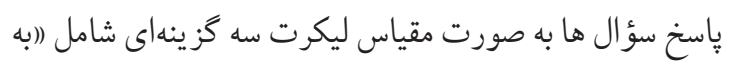

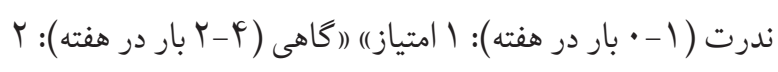

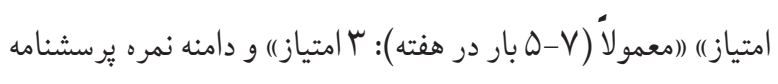

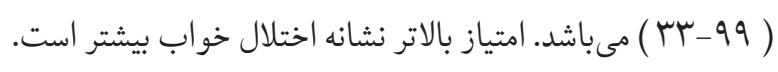

سومايه عظيمى را به هدر دهد، بلكه ناديده گرفتن نيازهاى اساسى

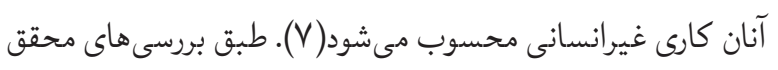
در خصوص اصلاح و ارتقاء وضعيت بهداشت خواب دانش آموزان تاكنون مطالعه مداخلهاى كه به صورت آموزش تركيبى ( شبكه اجتماعى براى مادران و بازى و سركرمى براى دانش آموزان) انجام

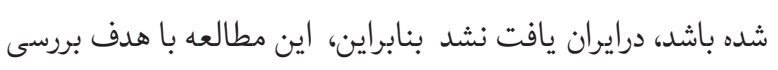

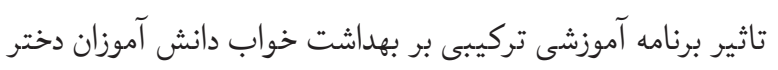
مقطع ابتدايى طراحى و اجرا كرديد.

مو اد و روشها جامعه هدف اين مطالعه نيمه تجربى (سال تحصيلى 9V-99)

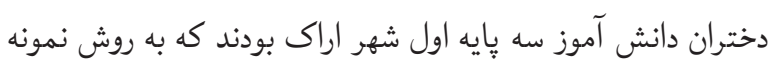

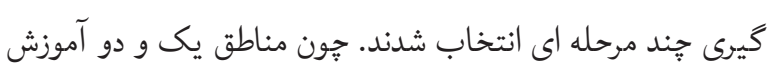
و يرورش شهر اراك بر اساس جمعيت شناختى تفاوت دارند در ابتدا

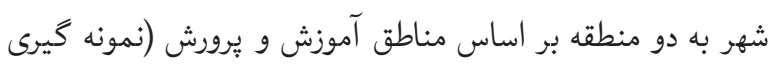
طبقه اى) تقسيم شدند سيس از هر منطقه (منطقه يك:، دو مدرسه ونه ابتدايى دخترانه به روش خوشهاى انتخاب شده (جمعا جهار مدرسه)

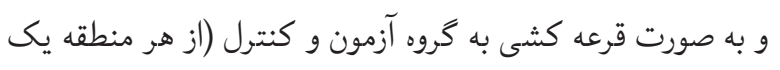

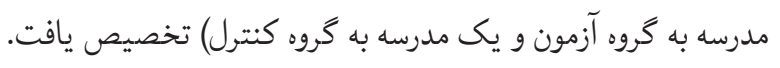

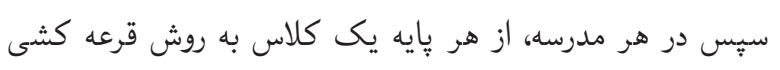
انتخاب شد و دانش آموزان كلاس در صورت تمايل وارد مطالعه شدند.

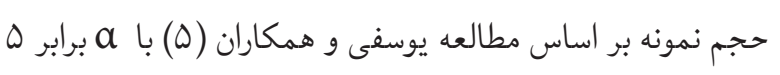

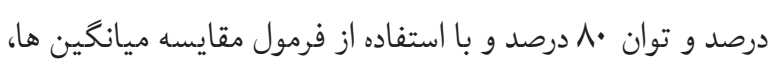

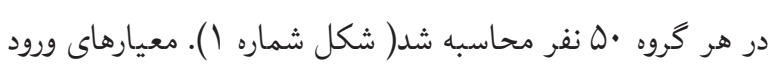
به مطالعه شامل: دانش آموزان دختر دوره اول مقطع ابتدايى، عدم

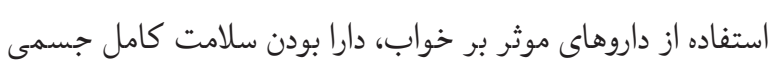

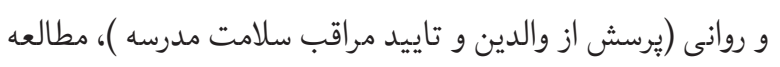
و امضاى فرم رضايت آكاهانه توسط والدين و تمايل دانش آموزان براى شركت در مطالعه بود. همجنين معيارهاى خروج از مطالعه ومانه

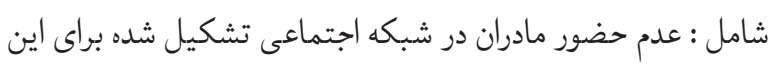

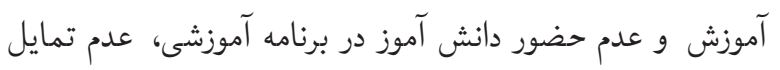




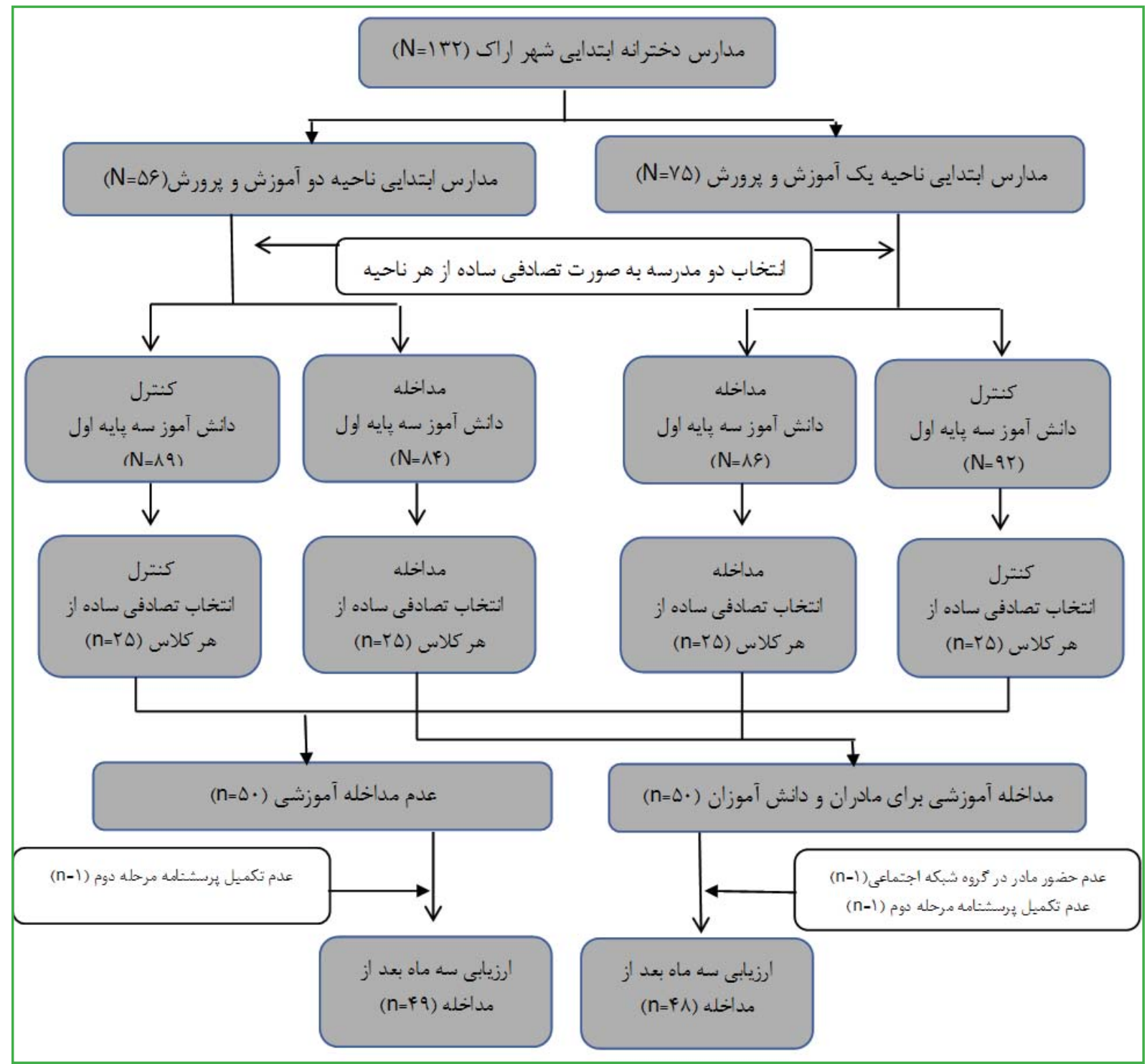

شكل ا. فرايند نمونه گَيرى و تخصيص افراد به دو كَروه مداخله و كنترل

روايى و يايايى (r=/9V) يرسشنامه در ايران توسط شوقى و كودكان شامل بازى و سركرمى تهيه كرديد. قبل از مداخله، ابتدا

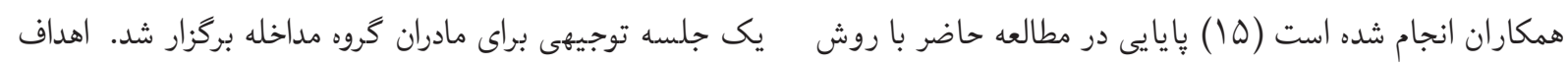

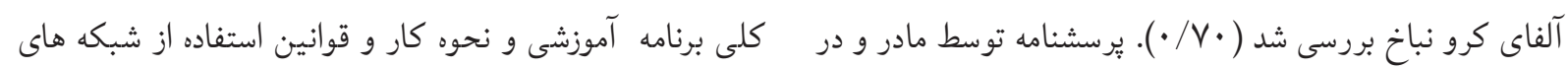

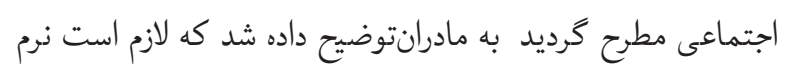
حضور محقق تكميل شد.

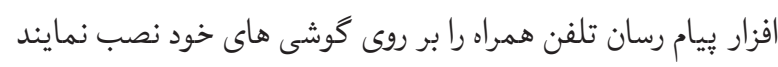

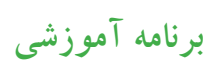

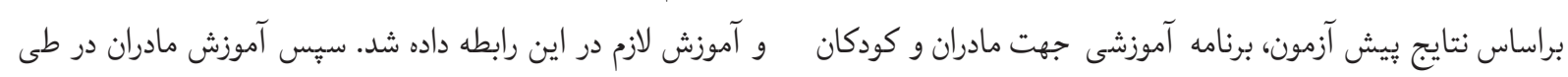

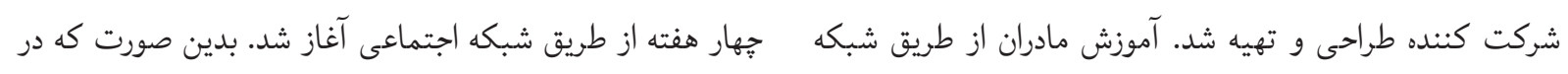

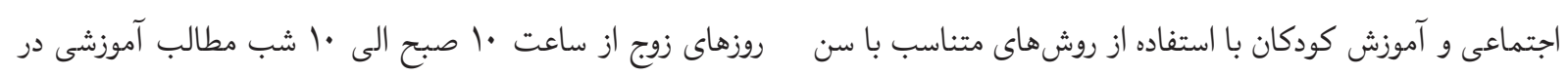


تكميل كرديد. براى حفظ اخلاق در يُوهش، بعد از اتمام مداخله

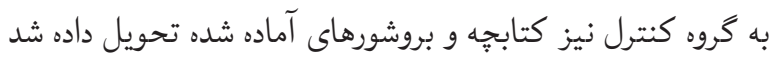
تا آنها نيز از آموزش بـى بهره نباشند.

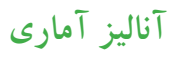

تجزيه و تحليل داده ها با استفاده از Y SPSS استفاده شد. در مطالعه

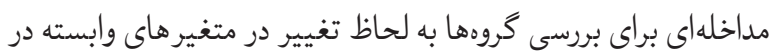

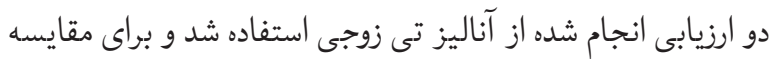

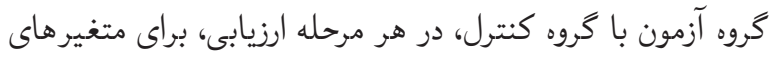

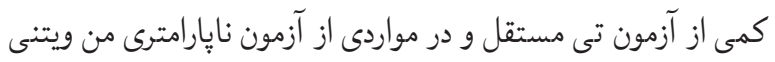
و براى ارزيابى متغيرهاى كيفى نيز از مربع كاى استفاده كرديد.
رابطه با بهداشت خواب كودكان توسط آموزش دهنده به اشتراك

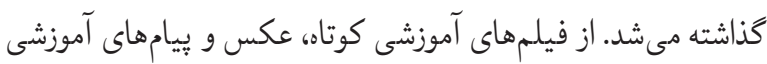

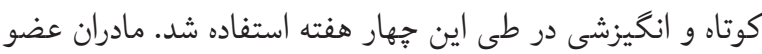
كروه در خصوص مطالب ارسالى به بحث و گفتخكو مى برداختند.

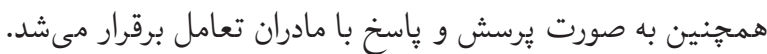

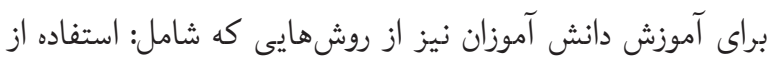

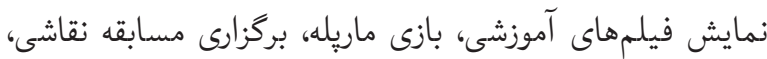

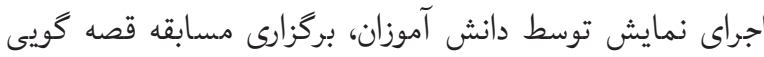
در رابطه با موضوع بهداشت خواب و فوايد خواب بود، استفاده شد بد بردي (جدول (). سه ماه بعد از مداخله مجددا برسشنامه ها توسط مادران

جدول ا. برنامه و محتوى آموزشى برَزار شده براى گَروه آزمون

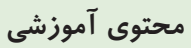

جلسه توجيهى حضورى

\begin{tabular}{|c|c|}
\hline 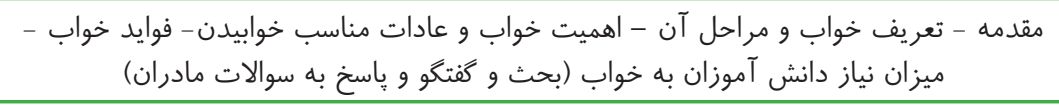 & هفته اول \\
\hline اختلالات خواب و عوامل موثر بر آن (بحث و كفتكو و پاسخ به سوالات مادران) & هفته دوم \\
\hline اصول بهداشت خواب دانش آموزان (بحث و گفتخو و ياسخ به سوالات مادران) & هفته سوم \\
\hline
\end{tabular}

آموزش در رابطه با موضوع بهداشت خواب به دانش آموزان به صورت پرسش و پاسخ حداقل به مدت يك يك ساعت

در هفته

\begin{tabular}{|c|}
\hline استفاده از نمايش فيلمهاى آموزشى متناسب با كروههاى سنى دانش آموزان \\
\hline 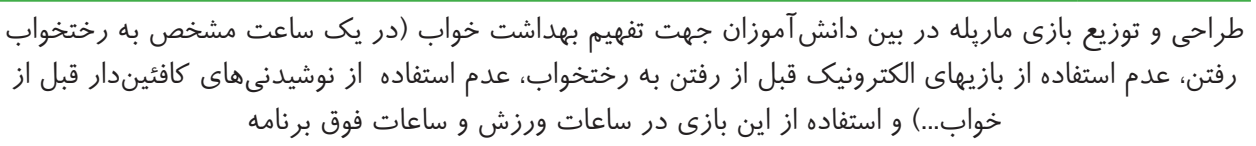 \\
\hline بركزارى مسابقه و نمايشكاه نقاشى با موضوع بهداشت خواب در بين دانش آموزان \\
\hline 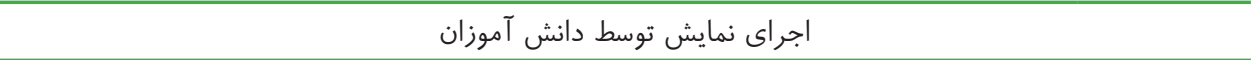 \\
\hline
\end{tabular}

ارائه نكات آموزشى كوتاه در مراسم صبحكاه دانش آموزى جهت كليه دانش آموزان در رابطه با رعايت اصول بهداشت خواب 
جدول r. مقايسه مشخصات دمو گر افيك متغير هاى كمى در دو گروه آزمون و كنترل قبل از مداخله آموزشى

\begin{tabular}{|c|c|c|c|c|c|}
\hline \multirow{2}{*}{$P$ value } & \multicolumn{2}{|c|}{ كروه كنترل } & \multicolumn{2}{|c|}{ كروه آزمون } & \multirow{2}{*}{ 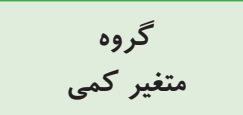 } \\
\hline & انحراف معيار & ميانگين & انحراف معيار & ميانگين & \\
\hline.$/ 9 \vee 0$ & $1 / \cdot V$ & $N / r$ & $\cdot / \wedge \varsigma$ & $V / 9 F$ & سن(سال) \\
\hline$\cdot /$ ero & 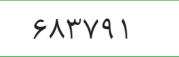 & |DQYTI. & s人Arq. & IFFDFVV & در آمدخانواده (تومان) \\
\hline .1901 & .190 & r & $\cdot / \lambda r$ & $1 / 9 r$ & تعداد سالهاى تحصيل \\
\hline ( & $F / F \Delta$ & 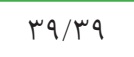 & $r / v 1$ & TN/TV & سن پدر(سال) \\
\hline$\cdot / V \Delta$ & $\Delta / \mu^{\mu}$ & $m F / q r$ & $F / r \mu$ & $\mu r / s$. & سن مادر(سال) \\
\hline$\cdot / \Delta F$ & $\cdot / S V$ & r/99 &.$/ 9 V Y$ & $\mathrm{r} / \mathrm{\Lambda \Lambda}$ & تعداد اعضاى خانواده \\
\hline
\end{tabular}

جدول س. مقايسه مشخصات دمو گرافيك متغير هاى كيفى در دو گروه آزمون وكنترل قبل از مداخله آموزشى

\begin{tabular}{|c|c|c|c|c|c|c|}
\hline \multirow[t]{2}{*}{$P$ value } & \multicolumn{2}{|c|}{ كروه كنتر ل } & \multicolumn{2}{|c|}{ كروه آزمون } & \multirow{2}{*}{\multicolumn{2}{|c|}{ متغير كيفى }} \\
\hline & درصد & تعداد & درصد & تعداد & & \\
\hline \multirow{5}{*}{.$/ 118$} & $r \cdot / \Lambda$ & $r$. & $1 \Lambda / \Lambda$ & 9 & زير ديڤلم & \multirow{5}{*}{ ميزان تحصيلات پِر } \\
\hline & fr/q & rl & $\mathrm{FV} / \mathrm{q}$ & 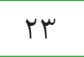 & ديڤلم & \\
\hline & $r$ & 1 & $\Lambda / \mu$ & F & فوق دييلم & \\
\hline & $1 r / r$ & 4 & $r \cdot / \Lambda$ & 1. & ل ل ل & \\
\hline & $r$ & 1 & $r / r$ & $r$ & فوق ليسانس & \\
\hline \multirow{5}{*}{$\cdot / \mathrm{rV}$} & سוץ & 10 & $r \Delta / f$ & IV & آزاد & \multirow{5}{*}{ شغل پِدر } \\
\hline & $r / r$ & $r$ & $r / r$ & $r$ & كشاورز & \\
\hline & $1 \wedge / \wedge$ & 9 & ro & ir & كارگر & \\
\hline & $\mathrm{rV} / \Delta$ & 11 & $r \Delta / \mathcal{F}$ & IV & 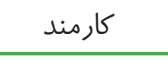 & \\
\hline & $\Lambda / r$ & $\Delta$ & . & $\cdot$ & ساير & \\
\hline \multirow{6}{*}{ 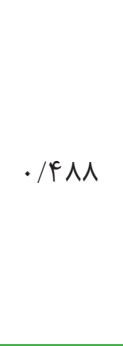 } & $r$ & 1 & . & . & 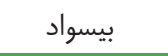 & \multirow{6}{*}{ ميزان تحصيلات مادر } \\
\hline & Tr/v & 19 & س س س & 19 & زير ديڤم & \\
\hline & 01 & ro & $r \Delta / \Lambda$ & rr & دييلم & \\
\hline & $r / 1$ & $r$ & $r / l$ & 1 & فوق دييلم & \\
\hline & $\Lambda / r$ & r & $1 \wedge / \wedge$ & 9 & ليسانس & \\
\hline & $r$ & 1 & $\cdot$ & . & فوق ليسانس & \\
\hline \multirow{2}{*}{$\cdot /$ fVq } & $1 \cdot / r$ & $\Delta$ & $4 / 4$ & r & 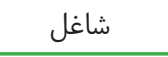 & \multirow{2}{*}{ شغل مادر } \\
\hline & $\wedge 9 / \wedge$ & pq & qH/1 & $r \Delta$ & خانه دار & \\
\hline
\end{tabular}

آزمون تى مستقل نشان داد ميانكين نمره عادت خواب قبل از خواب در كروه آزمون سه ماه بعد از آموزش به نسبت قبل از آن

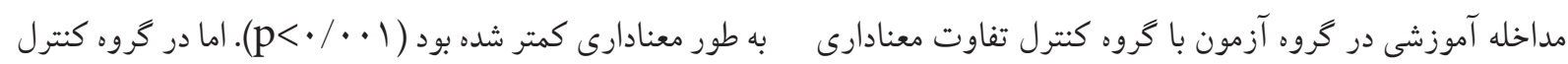

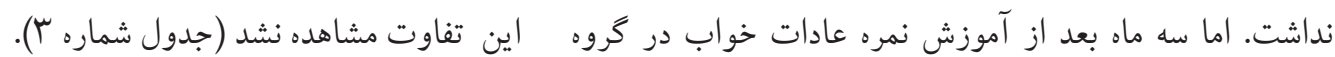

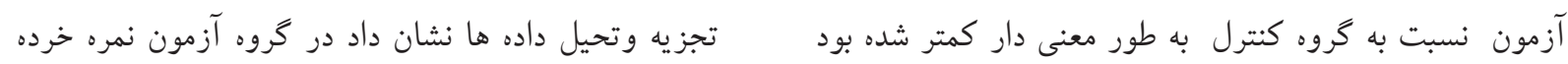

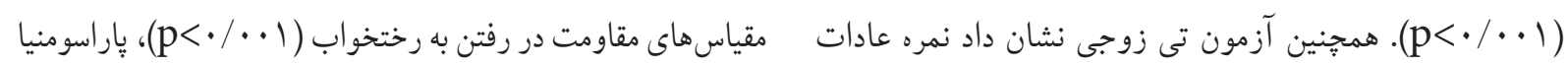


زمان خواب، اضطر اب خواب و اختلال تنفسى خواب در هيجٍكدام

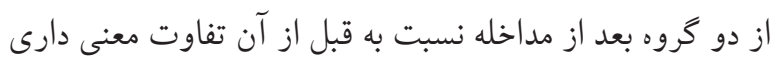

$$
\text { نداشتند (جدول شمارهץ). }
$$

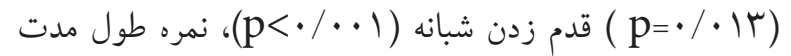

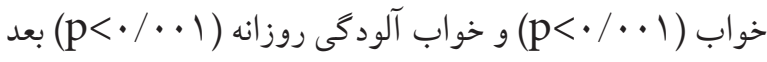

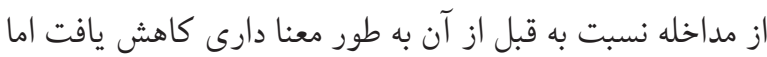

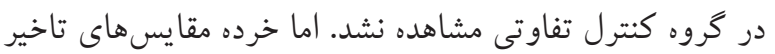
جدول عا. مقايسه ميانكَين و انحراف معيار در دو كَروه آزمون و كنترل قبل ازمداخله و سه ماه يِ از مداخله

\begin{tabular}{|c|c|c|c|c|}
\hline $\begin{array}{c}\text { P value } \\
\text { Paired t-test }\end{array}$ & انحراف معيار 土 ميانكين & انحراف معيار 土 ميانكين & زمان & متغير \\
\hline$\cdot / \cdot 1$ & $\wedge / \wedge \Delta \pm Y / \varsigma \vee$ & $11 / r V \pm r / q r$ & آزمون & \multirow{3}{*}{ مقاومت در رفتن به رختخواب } \\
\hline \multirow[t]{2}{*}{.$/ 4 \Delta$} & $1 \cdot / 99 \pm r / r \mu$ & $11 / r s \pm r / r r$ & كنترل & \\
\hline &.$/ . .1$ &.$/ 991$ & $P$ value $t$ test & \\
\hline$\cdot / \cdot \wedge \mu$ & 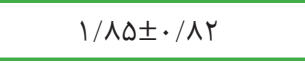 & 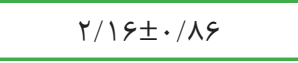 & آزمون & \multirow{3}{*}{ تاخير در شروع خواب } \\
\hline \multirow[t]{2}{*}{$\cdot /{ }^{*} V \mu$} & $r / \cdot \pm \pm \cdot / \Lambda \mathrm{V}$ & 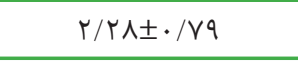 & كنترل & \\
\hline & $\cdot / \cdot \mathrm{VV}$ &.$/ 4 \vee q$ & $P$ value $t$ test & \\
\hline$\cdot / \cdot 1$ & $\Delta / \backslash \pm \Psi / \backslash \Lambda$ & $G / 1 \pm q Y / F r$ & آزمون & \multirow{3}{*}{ مدت زمان خواب } \\
\hline \multirow[t]{2}{*}{$.10 \cdot 9$} & $\varepsilon / 1 \pm \Delta \Lambda / r q$ & $\varsigma / 1 \pm s q / \mu V$ & كنتر ل & \\
\hline & $\cdot / \cdot 1$ & $\cdot / 1 \wedge$ & $P$ value $t$ test & \\
\hline . /OYA & 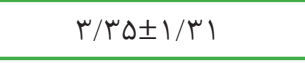 & $r / \uparrow \wedge \pm 1 / \uparrow \hookrightarrow$ & آزمون & \multirow{3}{*}{ اضطراب خواب } \\
\hline \multirow[t]{2}{*}{.1 .99} & $r / \mu \vee \pm 1 / \Delta q$ & $r / \& V \pm 1 / \uparrow q$ & كنترل & \\
\hline &.$/ 990$ & . /rTo & $P$ value $t$ test & \\
\hline.$/ .1$ & $r / l V \pm \cdot / \mu V$ & $F / \Delta F \pm \cdot / \Lambda$ & آزمون & \multirow{3}{*}{ بيدارى شبانه } \\
\hline \multirow[t]{2}{*}{. ISFF } & $p / \sim q \pm \cdot / v$. & $\varepsilon / \uparrow \Delta \pm \cdot / \vee q$ & 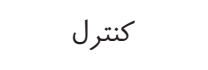 & \\
\hline &.$/ \cdot 1$ &.$/ \Delta S V$ & $P$ value $t$ test & \\
\hline.$/ \cdot 1 \mu$ & $\Lambda / r \Delta \pm 1 / r \mu$ & 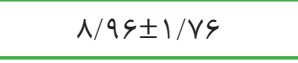 & آزمون & \multirow{3}{*}{ پِارا سومنيا } \\
\hline \multirow[t]{2}{*}{.$/ .94$} & $\Lambda / \sim q \pm 1 / \Delta 1$ & $9 / r \pm 1 \cdot / 18$ & كنترل & \\
\hline & $\cdot / \cdot r F$ &.$/ 918$ & $P$ value $t$ test & \\
\hline.$/ r r q$ & น/น $\Psi \pm / / 9$ & $r / \Delta S \pm 1 / \cdot r$ & آزمون & \multirow{3}{*}{ اختلال تنفسى خواب } \\
\hline \multirow[t]{2}{*}{.1011} & $r / r r \pm \cdot / \Delta \Lambda$ & $r / r \Lambda \pm \cdot / \varsigma V$ & كنترل & \\
\hline & $\cdot / \mu 1 \Lambda$ &.$/ 110$ & $P$ value $t$ test & \\
\hline.$/ \cdot 1$ & $\mid r / r V \pm r / F r$ & $\mid r / 1 \cdot \pm r / \cdot r$ & آزمون & \multirow{3}{*}{ خواب آلودگى روزانه } \\
\hline \multirow[t]{2}{*}{.$/ 1 \cdot 1$} & $\mid r / V \Psi \pm r / \uparrow \wedge$ & $\mid r / \Lambda \varsigma \pm r / \varsigma \Delta$ & كنترل & \\
\hline &.$/ \cdot 1$ &.$/ 1 r$ & $P$ value $t$ test & \\
\hline$\cdot / \cdots 1$ & $F \Delta / r^{f} \pm F / / F$ & $\Delta r / r I \pm \Delta / F F$ & آزمون & \multirow{3}{*}{ عادات خواب } \\
\hline \multirow[t]{2}{*}{.$/ 1 r r$} & $\Delta r / \Lambda \cdot \pm \varepsilon / \Lambda r$ & $\Delta F / F \Psi \pm \varepsilon / \| F$ & كنترل & \\
\hline &.$/ .1$ & $\cdot / r \cdot r$ & $P$ value $t$ test & \\
\hline
\end{tabular}


نظر بهبود بهداشت خواب موثر واقع شده است كه در اين مطالعه جهت دقيقهاى و كتابهاى داستانى با مفاهيم آموزشى استفاده شد و نتايج

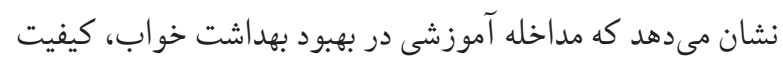

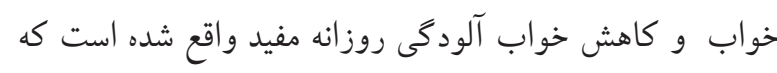

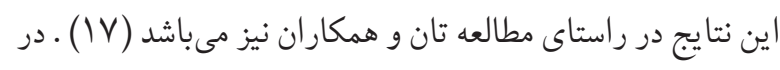

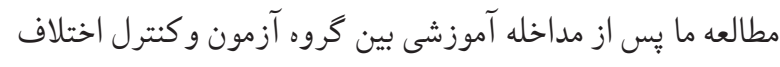
معنى دار ى در طول مدت خواب مشاهده شد كه در راستاى نتايج

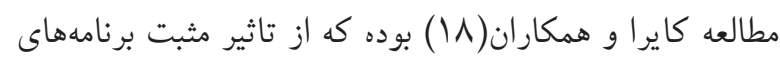
آموزش بهداشت خواب روى افزايش طول مدت خواب حمايت

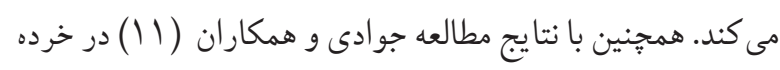
مقياس طول مدت خواب همخوانى دارد. اضطراب زمان خواب همني يكى از مواردى است كه در مطالعه ما دربين كروه آزمون و كنترل

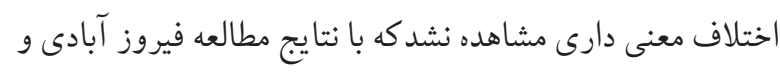

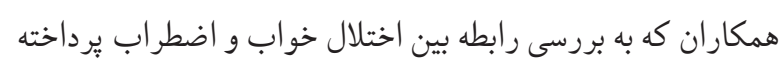

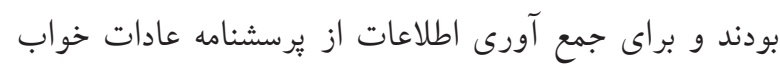

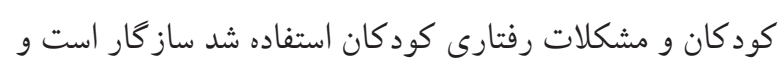

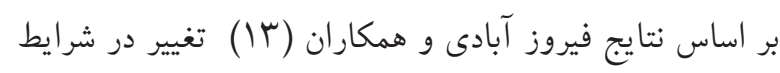

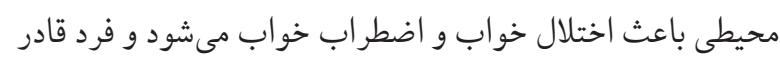
به خو ابيدن طولانى مدت نيست و افرادى كه در محيطهاى بر تنش

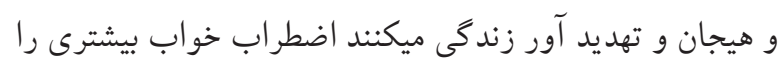
تجربه مى كنند و مىتوان كفت در مطالعه ما يكى از دلايل عدم

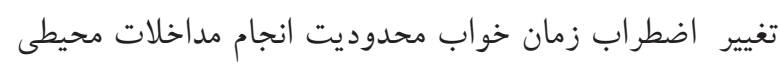

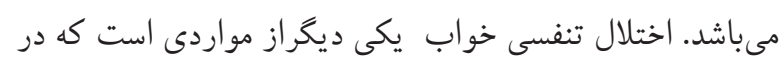

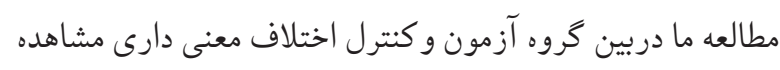
نشدكه با نتايج مطالعه امين شكروى و همكاران همخوانى دارد

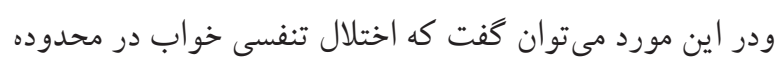

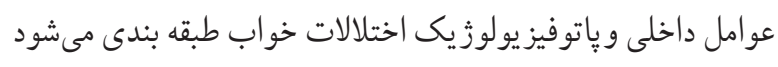
و لزوما مداخلات خارجى وتغيير عوامل بيرونى تاثيرى در فرايند

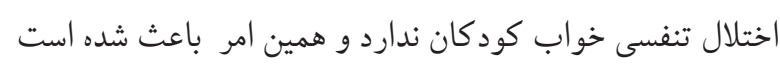

اين مطالعه با هدف تاثير برنامه آموزشى تركيبى بر بهداشت خواب

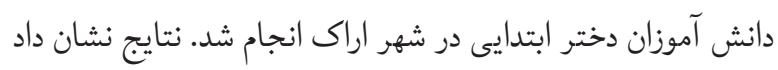

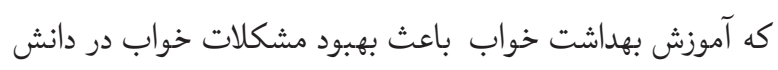

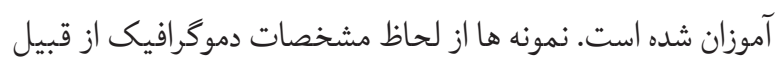
سن، جنس، شغل، سطح تحصيلات وغيره در گروههاى آزمون وكنترل ندونه همسان بوده و تغيير معنى دارى نداشتند. در اين مطالعه مداخله

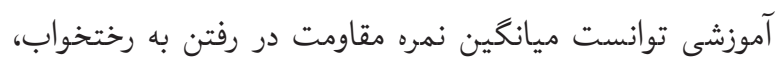
خواب آلودگى روزانه، هاراسومنيا، طول مدت خواب، بيدارى شبانه

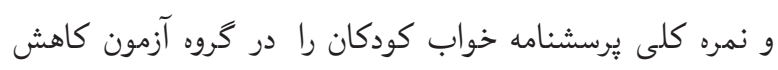

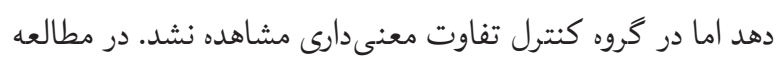

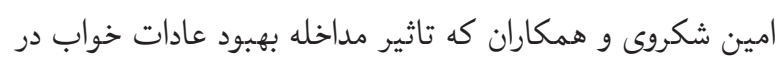

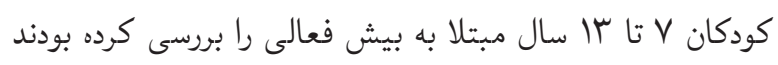

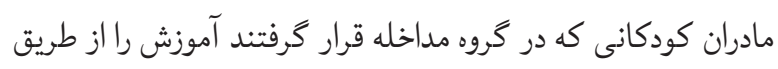
بوكلت و تماس تلفنى و متون آموزشى دريافت كردند و مادرانى كردي كردانى كه در كروه كنترل قرار داشتند مراقبت هاى بالينى روتين را دريافت

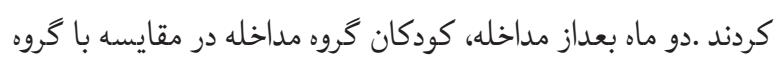

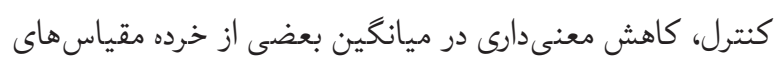

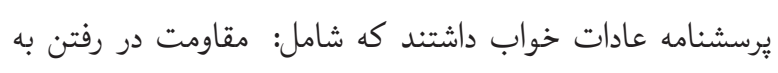
رختخواب، تاخير در شروع خواب، طول مدت خواب، اضطراب در

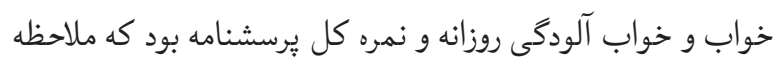
مىشود در مقايسه با مطالعه حاضر كه بر روى كودكان سالم انجام

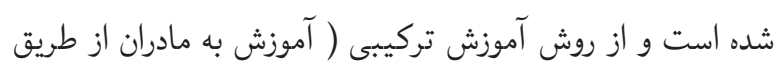

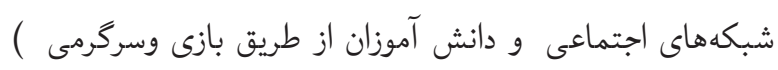

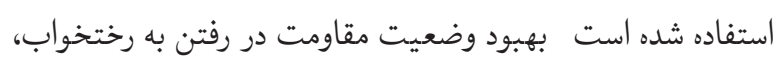
طول مدت خواب، خواب آلودكى روزانه و نمره كل يرسشنامه مشابه مىباشد. مطالعه مذكور بر خلاف مطالعه حاضر نتوانست تاثيرى لتردي

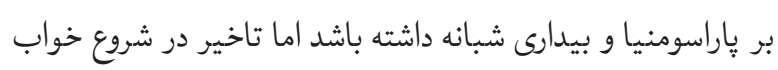

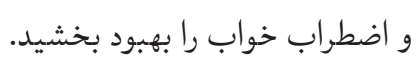

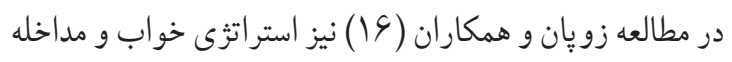
بهداشت خواب براى كودكان مبتلا به لوسمى لنفوبلاستيك حاد از 
كه به نظر آنها ايجاد تغييرات در الخوهاى خواب دشوار است و برنامهاى فشرده تر و با هدف قرار دادن گروههاى سنى مختلف مى تو اند مؤثر باشند

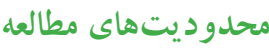

از جمله محدوديت هاى ثئوهش حاضر اين است كه گردآورى اطلاعات برسش نامه از طريق خودكزارش دهى بوده است، از اين رو بايد در تعميم نتايج احتياط نمود؛ هر جند با ارائه وقت كافى و بيان اهداف مطالعه به دانش آموزان تا حدودى اين مشكل برطرف كرديده است.

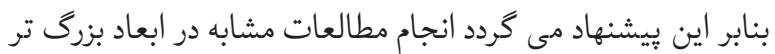

$$
\text { و گروه هاى سنى ديكر نيز صورت يذيرد. }
$$
نتيجه كيرى

يافتههاى ما نشان داد كه مداخله بهداشت خواب در بهبود عادات خواب دانش آموزان موثر بوده است و از اهداف كاربردى مطالعه جهت

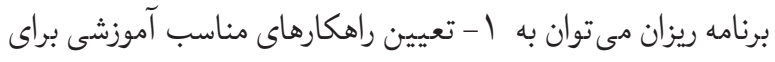

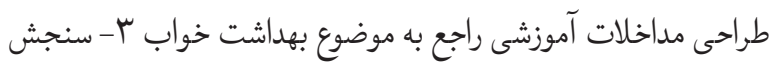

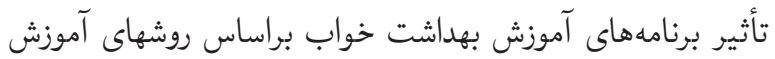

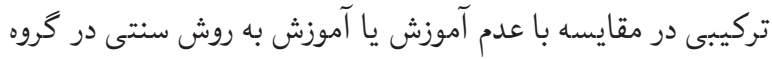

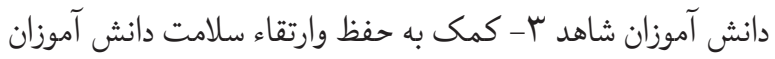
از طريق ايجاد عادات صحيح خواب اشاره كرد بدين ترتيب شايد با بررسى هاى بيشتر در سطح جامعه و موقعيت هاى مختلف بتوان

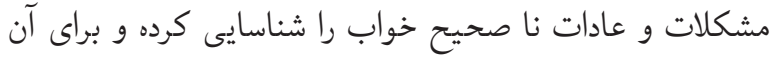
برنامه ريزى نموده و نسبت به رفع مشكلات اقدام نموده تا به اين

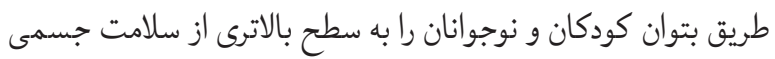
و روانى و اجتماعى رساندو آيندهاى بهتر را براى آنان فراهم ساخت. تضاد منافع در اين مطالعه تضاد منافع وجود ندارد تشكر وقدردانى اين مطالعه بركرفته از طرح تحقيقاتى مصوب دانشگاه علوم يزشكى اراى با كد اخلاق.1396.200. IR.ARAKMU.REC در مورخ

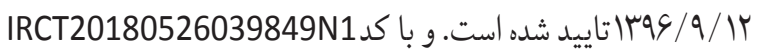
و حاصل بايان نامه دانشجويى ميباشد. از معاونت محترم يُوهشى بـ
كه كاهش معنى دارى در اختلال تنفسى خواب در پِ آزمون صورت نكرفته است. تاخير زمان خواب يكى ديكر از خرده مقياس ها يى است كه در مطالعه ما معنى دار نشده است كه در راستاى نتايج مطالعه جليل القدر و همكاران(19) كه به بررسى عادات

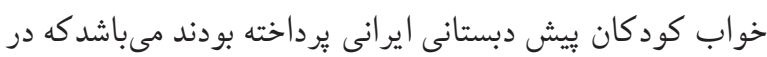

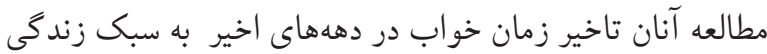
و مسايل شهرنشينى و فرهنگ مدرن مناطق شهرى مر تبط مىباشد كه جامعه امروز به يك جامعه تجارتى FF ساعته تبديل شده است

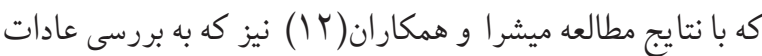
خواب كودكان دبستانى و تاثير آن روى الخوهاى خواب برداخته بودند همخوانى دارد. مى توان كفت يكى ديكر از دلايل تاخير زمان خواب در كودكان ايرانى حضور در جلسات خانو ادكى و مهمانى ها و به دنبال آن دير شام خوردن و درنهايت تاخير زمان خواب

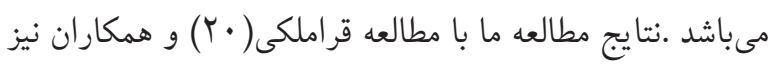
كه به بررسى الخوى خواب دانش آموزان 9-9 ساله ئ شهر تهران

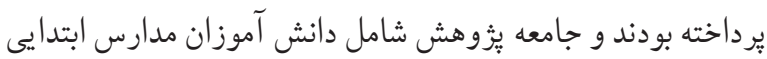
تهران بود. اطلاعات خواب كودكان با استفاده از دستخاه فعاليت

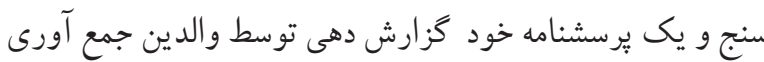

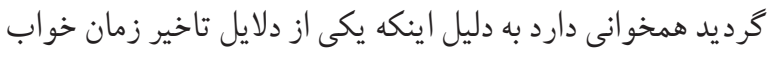

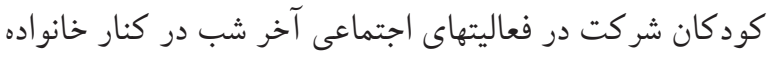
نظير تماشاى تلويزيون، بازيهاى كامييوترى و اينترنت مىباشد.

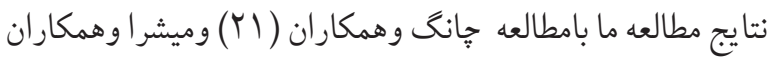
(Y) (I در زمينه حذف دستكاههاى الكترونيكى در محيط اتاق خواب كودى جهت كاهش تاخير زمان خواب و افزايش طول مدت خواب همخو انى دارد. در راستاى مطالعه ما نتايج مطالعه بناك و همكاران

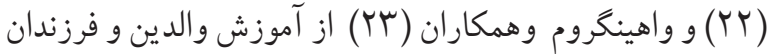
به منظور ارتقاء بهداشت خواب حمايت مى كند. نتايج مطالعه ما با مطالعه ريكنى و همكاران همخو انى ندارد و در مطالعه مداخلهاى ريكنى تغيير معنى دارى در وضعيت دانش و بهداشت خواب در

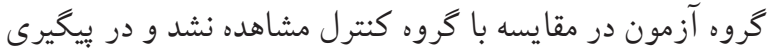
هيج تأثيرى بر روى دانش خواب و بهداشت خوراب مشاهده نشد برد 
آموزش ويرورش استان مركزى به سبب همكارى صميمانه در جهت

$$
\text { انجام تحقيق فوق تشكر و قدردانى ميكردد. }
$$

\section{References}

1. Roozbahani T, Noorian M, Saatchi K, Moslemi A. effects of Progressive Muscle Relaxation on sleep Quality in Pre-university students: A Randomized clinical Trial. scientific Journal of Hamadan nursing \& Midwifery facult 2016;24(1). [DOI:10.20286/nmj-24013]

2. Bahrami M, Dehdashti A, Karami M. A survey on sleep quality in elderly people living in a nursing home in Damghan city in 2017: A short report. Journal of Rafsanjan University of Medical Sciences. 2017;16(6):581-90.

3. Akbari Z, Mirzaei M. The Quantity and Quality of Sleep and their Relationship to metabolic syndrome. Journal of Mazandaran University of Medical Sciences. 2017;27(153):74-83.

4. Bahrami M, Dehdashti A, Karami M. Sleep quality and its causes and consequences from the perspectives of students residing in the dormitories of school of health: A cross-sectional study in Semnan university of medical sciences in 2016. Koomesh. 2018:96-104.

5. Yuosefgomrokchi M, Shafi poor Z, Paryad E, Atarkarruoshan Z. A Study of Sleep Habits of the Students of Primary Schools of Rasht City From Parents, Point of View. Journal of Holistic Nursing and Midwifery. 2009;19(2):40-5.

6. Modarresi MR, Faghihinia J, Akbari M, Rashti A. The Relation between Sleep Disorders and Academic Performance in Secondary School Students. Journal of Isfahan Medical School. 2012;30(206):1-12.

7. Jamshidian Z, Hasanpour M, Najafi M. The Effect of Sleep Hygiene Education on the Knowledge level of Parents of Elementary School Students. Health Prom Manage. 2017;1(4):61-8.

8. Mohammad Shahi M, Hosseini SA, Helli B, Haghighyzade $\mathrm{MH}$, Abolfathi $\mathrm{M}$. The effect of vitamin d supplement on quality of sleep in adult people with sleep disorders. Tehran University Medical Journal. 2017;75(6):443-8.

9. Rigney G, Blunden S, Maher C, Dollman J, Parvazian S, Matricciani L, et al. Can a school-based sleep education programme improve sleep knowledge, hygiene and behaviours using a randomised controlled trial. Sleep medicine. 2015;16(6):736-45. [DOI:10.1016/j. sleep.2015.02.534] [PMID]

10. Wang XT, Yi Z, Kang V, Xue B, Kang N, Brewer G, et al. Messaging affects sleep and school performance in
دانشگاه علوم يزشكى اراك جهت تأمين بودجه طرح مذكور، از همكاران هيئت علمى دانشكده بهداشت اراك، به جهت همكارى در تنظيم و انجام اين بيزوهش و كليه مسئولين و كاركنان سازمان

Chinese adolescents. Health Behavior and Policy Review. 2017;4(1):60-6.. [DOI:10.14485/HBPR.4.1.7]

11. Javadi $M$, Javadi A, Kalantari $N$, Jaliloghadr S, Mohamad $H$. Sleep problems among pre-school children in Qazvin, Iran. The Malaysian journal of medical sciences. 2014;21(6):52.

12. Mishra A, Pandey RK, Minz A, Arora V. Sleeping habits among school children and their effects on sleep pattern. Journal of caring sciences. 2017;6(4):315. [DOI:10.15171/ jcs.2017.030] [PMID] [PMCID]

13. Firoozabady EE, Zarch MK, Afshani SA, Halvani A. The prevalence of sleep disorders and their relationship with anxiety and behavioral problems among primary school students in Yazd, Iran. Int J Pediatr. 2015;3(3-1):625-31.

14. John B, Bellipady SS, Bhat SU. Sleep promotion program for improving sleep behaviors in adolescents: A randomized controlled pilot study. Scientifica. 2016. [DOI:10.1155/2016/8013431] [PMID] [PMCID]

15. Amin Shokravi F, Hakim Shooshtari M, Shahhatami H. The impact of a sleep hygiene intervention on sleep habits in children with attention deficit/hyperactivity disorder. International Journal of Pediatrics. 2016;4(12):4117-26.

16. Zupanec S, Jones H, McRae L, Papaconstantinou E, Weston J, Stremler R. A sleep hygiene and relaxation intervention for children with acute lymphoblastic leukemia: a pilot randomized controlled trial. Cancer nursing. 2017;40(6):488. [DOI:10.1097/NCC.0000000000000457] [PMID] [PMCID]

17. Tan E, Healey D, Gray AR, Galland BC. Sleep hygiene intervention for youth aged 10 to 18 years with problematic sleep: a before-after pilot study. BMC pediatrics. 2012;12(1):189. [DOI:10.1186/1471-2431-12189] [PMID] [PMCID]

18. Kira G, Maddison R, Hull M, Blunden S, Olds T. Sleep education improves the sleep duration of adolescents: a randomized controlled pilot study. Journal of Clinical Sleep Medicine. 2014;10(07):787-92. [DOI:10.5664/jcsm.3874] [PMID] [PMCID]

19. Jalilolghadr S, Hashemi S, Javadi M, Esmailzadehha $\mathrm{N}$, Jahanihashemi $\mathrm{H}$, Afaghi A. Sleep habits of Iranian pre-school children in an urban area: Late sleeping and sleep debt in children. Sleep and Biological Rhythms. 2012;10(2):154-6. [DOI:10.1111/j.1479- 
8425.2011.00516.x]

20. gharamalekl A, hoseini M, zamani A, vaez zadeh F, Ggafarian K. Sleep Pattern in 6-9 Years Old Students Living in Tehran City. Journal of Isfahan Medical School. 2011;29(154):1-9.

21. Chung S, Wilson K, Miller A, Johnson D, Lumeng J, Chervin R. Home Sleeping Conditions and Sleep Quality in LowIncome Preschool Children. Sleep Medicine Research. 2014;5(1):29-32. [DOI:10.17241/smr.2014.5.1.29]

22. Bonuck K, Schwartz B, Schechter C. Sleep health literacy in head start families and staff: exploratory study of knowledge, motivation, and competencies to promote healthy sleep. Sleep Health. 2016;2(1):19-24. [DOI:10.1016/j.sleh.2015.12.002] [PMID] [PMCID]

23. Wahyuningrum E, Rahmat I, Hartini S. Effect of Health Education of Sleep Hygiene on Sleep Problems in Preschoolers. Belitung Nursing Journal. 2018;4(1):68-75. [DOI:10.33546/bnj.208] 